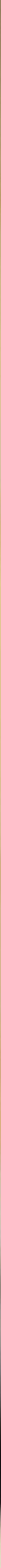




\title{
EL RESURGIMIENTO DE LA PROGRESIVIDAD «EFECTIVA»AL DESCUBIERTO: ¿UNA TENDENCIA INTERNACIONAL DE NUESTROS DÍAS?
}

\author{
María Amparo Grau Ruiz \\ Catedrática de Derecho Financiero y Tributario \\ Universidad Complutense de Madrid (España) \\ Directora de la Revista Técnica Tributaria
}

La necesidad de contar con recursos suficientes para financiar el gasto público necesario en aras del desarrollo sostenible tras la pandemia está llevando a diversos organismos internacionales a ofrecer múltiples orientaciones a los Gobiernos de todo el mundo sobre cómo conseguir fondos adicionales mediante la puesta en marcha de posibles reformas tributarias. Desde luego, las opciones disponibles son muy variadas y su acomodo a los distintos sistemas dependerá de la concreta situación de cada Estado (a menudo se distingue entre economía avanzada, emergente o en desarrollo a la hora de fijar los destinatarios de algunas recomendaciones específicas). No obstante, con carácter general, llaman la atención algunas propuestas expresadas más o menos abiertamente, que se escuchan de manera reiterada en distintos foros en los últimos meses, razón por la que conviene dedicarles estas páginas.

Si nos fijamos, de entrada, en las apuestas del Fondo Monetario Internacional (en adelante, FMI), éstas comprenden los impuestos sobre la renta personal y sobre sociedades, junto con los tributos que gravan la propiedad y el consumo. En los primeros sobre la renta, en el caso de personas físicas, se propone fijar umbrales de exención por debajo del PIB per cápita, restringir las deducciones generalizadas, subir los tipos marginales altos - si es factible-, e introducir recargos temporales (en economías avanzadas). En el caso de sociedades, conscientes de la presión que soporta este impuesto ${ }^{1}$, se sugiere racionalizar los incentivos fiscales basados en el beneficio para atraer inversión directa extranjera,

1 De Mooij, R.; Klemm, A.; Perry, V. (eds.) (2021) Corporate Income Taxes under pressure, Why reform is needed and how it could be designed, FMI, Washington D.C. 
racionalizar los incentivos especiales para PYMEs, usar medidas anti-abuso contra el desvío de beneficios, introducir tributos sobre el exceso de beneficios, o colocar a las industrias extractivas en regímenes especiales (en países emergentes y otros con bajos ingresos). Por lo que respecta a los impuestos sobre la propiedad, se señalan como posibilidades las siguientes: subir los tipos de gravamen, actualizar los valores a los precios de mercado, reforzar los registros y la capacidad administrativa (en economías emergentes y con bajos ingresos), y reforzar los impuestos sobre sucesiones y donaciones (en países avanzados). En lo tocante a los impuestos sobre el consumo, se indican vías como la potencial reducción de las exenciones y los tipos cero en el caso del IVA aplicable a algunos bienes y servicios; el reforzamiento de las accisas con un mejor diseño, ejecución y tipos más elevados (en economías no avanzadas); y la introducción o el aumento de los impuestos sobre el carbono.

Centrándonos, en lo sucesivo, en el análisis realizado en relación con los impuestos sobre la renta, pronto se advierte que se recurre a un dato de partida revelador: la fuerte caída de los tipos marginales más altos tanto para el trabajo y el capital desde la década de los 80, así como de los tipos nominales del impuesto sobre sociedades, conforme se observa en el siguiente cuadro de la OCDE, básicamente referido al IRPF (PIT) y al IS (CIT). Igualmente, se incluyen en el diagrama barras sobre las consecuencias del tratamiento recibido por dividendos e intereses, que diverge claramente del de las ganancias de capital.
Figure 2.12. OECD: Top Income Tax Rates

(Percent)

The top marginal lax rates for both labor and capital income have declined sharply since the 1980s.

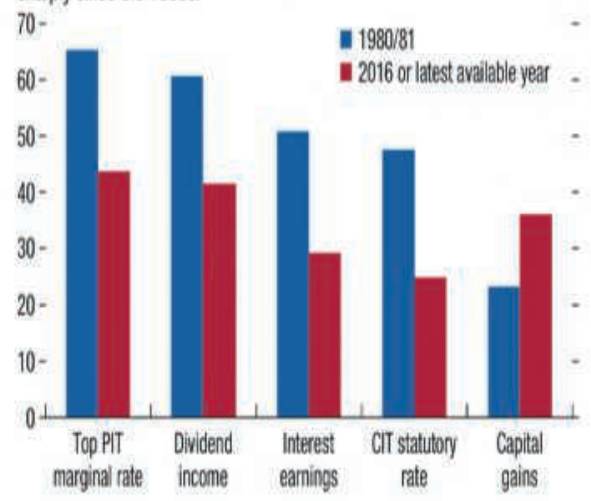

Sources: Carey, Chouraqui, and Hegemann 1993; and Harding and Marten 2018. Note: $\mathrm{CT}=$ = corporate income tax; $0 \mathrm{OCCO}=$ Organisation for EComomic CO-operation and Development, PIT = personal income tax.

A este respecto, el FMI ha recordado que gravar las rentas de capital (intereses, dividendos y ganancias) puede servir indirectamente para aumentar la progresividad efectiva, incluso con un tipo proporcional.

Evidentemente, el aludido proceso de «racionalización» (que no de indiscriminada eliminación) de los incentivos fiscales es una forma sobradamente conocida de intentar lograr la expansión gradual de la base del impuesto sobre la renta de sociedades. El contexto internacional actual parece ciertamente favorable a este modo de proceder, en la medida en que la cooperación internacional y el acuerdo sobre tributación societaria mínima pueden ayudar a contener una mayor competencia fiscal, permitiendo a los países mantener tipos más altos y reducir los gastos fiscales.

En lo referente a los tipos nominales del impuesto sobre sociedades, un repaso histórico 
muestra un claro descenso generalizado en las últimas dos décadas, conforme se recoge en el informe de la OCDE aparecido en julio de este mismo año y elaborado a partir de sus estadísticas hasta la fecha 2 : de 111 países, 94 tienen un tipo impositivo más bajo en 2021 que en 2000, 13 lo mantienen igual y 4 lo han subido.

Ahora bien, curiosamente no sólo se trata de restaurar la base imponible sobre la que aplicar tipos consistentes o previsiblemente al alza en el futuro, sino que se va todavía un paso más allá. Se vislumbran en el horizonte, como antes se ha dicho, nuevos tributos sobre los excesos de beneficios, frecuentemente mencionados con la expresión inglesa excess corporate profit taxes, que en su configuración pueden ser «añadidos a» (en el afán de reforzar la cualidad de progresivo del sistema en su conjunto) o «en lugar del» impuesto sobre sociedades (cuyo detalle convendría valorar en última instancia también en relación con esta característica). Ello invita, además, a replantearse la noción central de beneficio en la imposición societaria y la correcta adecuación de las reglas para su cálculo. En efecto, la definición de estos excesos fundamentalmente se hace coincidir con las rentas económicas que exceden el retorno mínimo exigido por los inversores. Se argumenta que el objetivo es asegurar una contribución de las empresas que han prosperado durante la crisis (por ejemplo, las farmacéuticas y las altamente digitalizadas), sin afectar a otras empresas (y trabajadores) que obtienen beneficios mínimos o pérdidas.

Esta propuesta de giro hacia una tributación más progresiva se ha hecho por el FMI teniendo en cuenta los resultados de una encuesta previa $^{3}$ y algunas estimaciones de su propio personal. A raíz de todo esto, ha apreciado una preferencia por la progresividad en quienes mayoritariamente respondieron de forma negativa a la pregunta de si la carga fiscal era demasiado elevada en el caso de quienes obtenían rentas altas, incluso antes de la pandemia, tanto en economías avanzadas (en un total de 23) como emergentes (en 12).

De hecho, la extendida preocupación por la insuficiencia de muchos sistemas tributarios para reducir la desigualdad también ha impulsado a la Comisión Económica para América Latina y el Caribe (CEPAL) a promover «una agenda de reformas que permitan ejecutar las políticas fiscales activas necesarias para el desarrollo sostenible». Dado que el impuesto sobre la renta tiene un diseño progresivo, concluye que su evasión es regresiva. CEPAL, en consecuencia, recomienda igualmente fortalecer el impuesto sobre la renta personal y empresarial, al tiempo que se revisa el uso de los incentivos fiscales y gastos tributarios ${ }^{4}$.

\footnotetext{
2 OCDE (2021) Corporate Tax Statistics: Third Edition, Informe publicado el 29 de julio de 2021, OCDE, París. Más información disponible en el siguiente enlace: https://www.oecd.org/tax/tax-policy/ corporate-tax-statistics-database.htm [último acceso 10 de septiembre de 2021].

3 IMF, International Social Survey Program 2016.

4 También estima «fundamental considerar la extensión del alcance de los impuestos sobre el patrimonio y la propiedad como instrumentos para movilizar recursos y reducir la desigualdad» ONU (2021) Panorama fiscal de América Latina y el Caribe. Los desafíos de la política fiscal en la recuperación transformadora pos-COVID-19, Comisión Económica para América Latina y el Caribe (CEPAL).
} 
Si se comparan a continuación los datos de la OCDE y la CEPAL sorprende percatarse de la gran diferencia en el IRPF (se recauda el equivalente a un $8,1 \%$ del PIB frente al $1,8 \%$ respectivamente), lo que impacta en el éxito de la redistribución lograda en los distintos países. Por el contrario, en lo concerniente a la renta «corporativa», la recaudación promedio es levemente superior en América Latina, como se refleja en el siguiente gráfico.

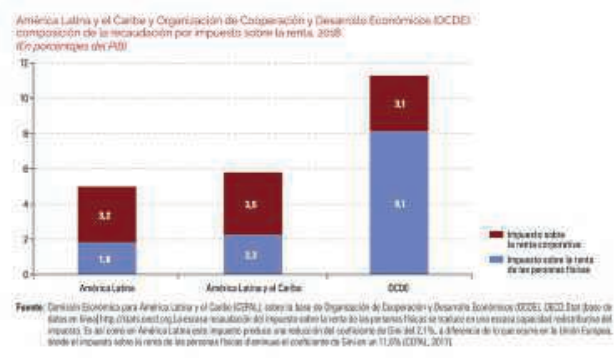

A la vista de los planteamientos expuestos, bien podría pensarse que el deseo de reanimar estos impuestos sobre la renta obedece a la razón de una sospechada extenuación al poderse haber quedado su potencia recaudatoria debilitada tras el Covid-19. Sin embargo, aunque pueda resultar extraño, el Centro Interamericano de Administraciones Tributarias (CIAT) ha puesto de manifiesto últimamente que la recaudación que más ha aumentado en términos acumulados es la de los impuestos sobre la renta (si bien habiendo contemplado de manera agregada la de personas y de sociedades por la dificultad de separación de fuentes) ${ }^{5}$.

En fin, una mayor dosis de progresividad se nos presenta a menudo como efugio. Pero no debe olvidarse que la salida que busca reforzar la capacidad tributaria, expandiendo gradualmente la base del IS en un sistema fiscal más progresivo, aumentando la recaudación con el propósito de sortear dificultades económicas, puede tener alguna contrapartida inesperada. Actualmente es sabido que en muchas economías el sector empresarial está sobre-endeudado y debilitado, sobre todo, las pequeñas empresas. De ahí la importancia de equilibrar los riesgos de deuda pública y privada creciente con los de la retirada prematura del apoyo fiscal, que podría ralentizar la recuperación. Como reconoce el FMI, hasta que se controle la pandemia globalmente, la política fiscal ha de permanecer flexible, apoyando a los sistemas de salud, los hogares más afectados, las empresas viables, y la recuperación económica. Insiste esta institución en que los marcos fiscales creíbles a medio plazo pueden abrir un camino para reconstruir los colchones fiscales a un ritmo dependiente de la fuerza de la recuperación ${ }^{6}$.

De ahí la necesidad, a pesar de la urgencia, de sopesar el mantenimiento del apoyo fiscal bien dirigido, sin cambios repentinos en el sistema fiscal que puedan afectar al ritmo de la ansiada recuperación, y

5 Debe precisarse que la evolución mensual difiere según se comparen datos con meses muy afectados por la pandemia y se tomen en consideración los aplazamientos. Lidera España el crecimiento en algún supuesto. Díaz de Sarralde Miguez, S.; López, J.; Maldonado, G. (2021) Reporte de recaudación Covid-19 (RRC) $1^{\text {er }}$ cuatrimestre 2021, Documentos de Trabajo CIAT 3, julio 2021.

6 FMI (2021), Fiscal monitor, abril 2021. Cabe destacar la perspectiva del IMF Executive Board Discussion of the Outlook: «providing well-targeted fiscal support». «Policymakers would need to emphasize measures that limit scarring from the crisis, shrink inequality and boost productive capacity». "The transition from support measures would need to be managed carefully to avoid sudden cliffs that could derail the recovery». 
también de fomentar la capacidad productiva. Obviamente cualquier medida dirigida debe adoptarse a medida de la capacidad administrativa de los países, mejorando la transparencia y la rendición de cuentas.

Si traemos a colación el caso alemán ${ }^{7}$, como mero ejemplo de Derecho comparado, aunque su fuerza tractora sea relativamente limitada en nuestro entorno, interesa subrayar el esfuerzo de su Gobierno por mantener la solvencia de las empresas viables y facilitar el tránsito de trabajadores, cuidando especialmente la dimensión temporal en el mantenimiento y la eliminación gradual del apoyo público (ya que las reducciones temporales hacen que los agentes acomoden su conducta consecuentemente), con un ritmo de retirada flexible y generoso. Alemania ha diseñado medidas específicamente dirigidas a reasignar recursos post-crisis, por ejemplo, el aumento en la compensación de las pérdidas de las sociedades (tax loss carry-back: de 5 a 10 millones euros en los años 2020 y 2021) o incentivos a la innovación.

Con todo, las propuestas de los organismos internacionales a las que hemos hecho referencia dan la impresión de haber sido concebidas con un enfoque que peca de incompleto por desfasado (quizás susceptible de ser calificado como tax as usual) dado que parecen ignorar un concepto más amplio de progresividad «efectiva», que habría de calibrarse en toda su extensión, teniendo también en cuenta otros aspectos como los ambientales, por ejemplo. Efectivamente el citado enfoque se queda un poco retrasado respecto de las actuales circunstancias en las que ya no suele aceptarse el criterio business as usual en las corrientes imperantes en el mundo financiero privado (que así adelanta al público).

En esta línea de pensamiento, interesa resaltar que el paquete de medidas presentado por la Comisión Europea para contribuir a mejorar el flujo de dinero hacia actividades sostenibles en la Unión Europea en línea con el Pacto Verde Europeo y los Objetivos de Desarrollo Sostenible incluye una propuesta de Directiva de información de las empresas en materia de sostenibilidad ${ }^{8}$ (nótese que ya no se denomina de «información no financiera», porque es notorio que esta información sí tiene relevancia financiera).

Es inevitable que esta ola de propensión a considerar la sostenibilidad acabe afectando de algún modo a la configuración del alcance de los principios tributarios sobre los que comúnmente se asientan los sistemas «modernos», que ahora deben combinar las aspiraciones y medios existentes desde principios del siglo XX con los del XXI, actualizándose. Baste recordar que, en el pasado trimestre, en el seno del Parlamento Europeo, el Comité de Asuntos Económicos y Monetarios ha debatido infructuosamente sobre cómo

7 FMI (2021) Germany, 2021 Article IV Consultation IMF, Country Report No. 27/153, Washington D.C., 14 de julio de 2021.

8 Modificará las Directivas 2013/34/UE, 2004/109/CE, 2006/43/CE y el Reglamento (UE) n. ${ }^{\circ}$ 537/2014. COMUNICACIÓN DE LA COMISIÓN AL PARLAMENTO EUROPEO, AL CONSEJO, AL COMITÉ ECONÓMICO Y SOCIAL EUROPEO Y AL COMITÉ DE LAS REGIONES, Taxonomía de la UE, divulgación de información corporativa en materia de sostenibilidad, preferencias de sostenibilidad y obligaciones fiduciarias: Orientar la financiación hacia el Pacto Verde Europeo. COM/2021/188 final 21.4.2021. 
reajustar el sistema tributario para apoyar también objetivos

ambientales, siendo uno de los puntos críticos cuánto aumento de la presión fiscal (o dicho de otro modo, qué medida de progresividad -con la inclinación a considerarla en los términos en que ha sido tradicionalmente entendida-) es admisible a futuro y cómo acompasarla eficazmente (a través de una verdadera progresividad efectiva) con los nuevos tiempos que requieren la orientación de los sistemas fiscales simultáneamente en varias direcciones determinadas para surtir los efectos esperados ${ }^{9}$.

9 «A principios del siglo XX, en la mayoría de los países industrializados, el objetivo de justicia fiscal se plasmó en un proyecto de impuesto progresivo para que tributaran más quienes más ganan. Sin embargo, desde hace décadas se vienen observando estrategias de elusión fiscal por parte de la población más acomodada, a expensas del aumento de la presión fiscal sobre los hogares más pobres. Además, la tributación no progresiva ha ido en aumento, y el principal ejemplo de ello es el impuesto sobre el valor añadido.

Por eso pedimos a los Estados miembros que mejoren el rendimiento del impuesto sobre la renta de las personas físicas, especialmente de las más acomodadas, al tratarse del impuesto más progresivo». Parlamento Europeo -Comisión de Asuntos Económicos y Monetarios-, PROYECTO DE INFORME sobre la creación de un sistema fiscal europeo económica, social y ecológicamente sostenible en la economía tras la COVID-19 (2020/2259(INI)), ECON_PR(2021)662098, Ponente: Claude GruffatVotación y rechazo el 03.06.2021. Texto disponible en https://www.europarl.europa.eu/doceo/ document/ECON-PR-662098_ES.html [Último acceso 10 de septiembre de 2021]. Sobre los extremos en torno a los que versa la principal discusión en estos momentos en el plano internacional, puede consultarse OCDE (2021), OECD Secretary-General Tax Report to G20 Finance Ministers and Central Bank Governors - julio de 2021-, OCDE, París, www.oecd.org/tax/oecd-secretary-general-tax-reportg20-finance-ministers-july-2021.pdf. ONU (2021) La UE debería considerar el impacto del nuevo mecanismo de cambio climático en el comercio mundial, Conferencia de las Naciones Unidas sobre Comercio y Desarrollo, Ginebra. https://unctad.org/es/news/la-ue-deberia-considerar-el-impacto-delnuevo-mecanismo-de-cambio-climatico-en-el-comercio [Último acceso 10 de septiembre de 2021].» 
